
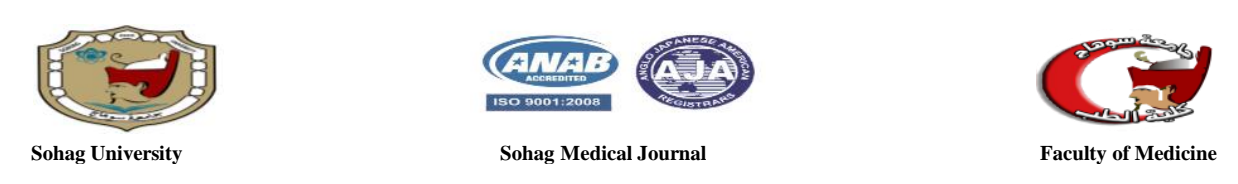

\title{
Did the COVID-19 pandemic start much earlier than expected?
}

\author{
Ahmed Roshdy Alagamy Radwan \\ Lecturer of Rheumatology, Sohag University
}

\begin{abstract}
:
Introduction: The COVID-19 pandemic is now rapidly growing, with over one million and 300 thousands infected persons and over 75,000 deaths all over the world. Case experience: We were asked to see a male patient in late December 2019 by a colleague specialized in chest medicine. The patient was medical person, with history of direct contact to people from many different countries. He was middle aged, diabetic and presented to chest doctors as a case of severe pneumonia and resistant fever. He received many combinations of antibiotics and antiviral therapies, but with no improvement, and finally he needed to be ventilated. Knowing some idea about the pathogenesis of COVID-19 disease raised this question in our minds: Could this patient be an undiagnosed COVID-19 case?

Conclusion: COVID-19 may be present inside human beings long before its actual discovery in late 2019, and many of the undiagnosed severe respiratory symptoms may had COVID-19. The actual prevalence of COVID-19 may be much wider than the recorded numbers all over the world, and this means that the mortality rate of this virus is much lower than recorded because many cases may pass asymptomatic and not included in the total number of COVID-19 cases. We may have reached already the herd immunity target, and COVID-19 may have reached its peak spread, especially in countries with earlier exposure to it.
\end{abstract}

Keywords:Corona virus, COVID-19, Pandemic

\section{Background}

Coronaviruses are enveloped, singlestranded large RNA viruses that infect humans, but also a wide range of animals (1).

Human coronaviruses (HCoVs) represent a major subtype of the wider group coronaviruses (CoVs) (2). However, many of the CoVs can not affect human. HCoVs are associated with varying respiratory manifestations, fro$m$ the common cold up to severe devastating pneumonia and bronchiolitis (2). Due to their high genomic substitution and mutation rates; $\mathrm{HCoVs}$ are recognized as one of the most rapidly evolving viruses (3). Until now, seven HCoVs strains are discovered so far, with 4 cause mild to moderate flu-like symptoms and 3 are associated with more severe lower respiratory symptoms $(4,5)$.

Since the beginning of the $21^{\text {st }}$ century and maybe even before, many new factors helped more rapid evolution of HCoVs including urbanization and poultry farming, along with some strange dietary habits; especially in China. All these factors, combined with the nature of the HCoVs led to frequent mixing of species and facilitated the crossing of species barrier and genomic recombination of these viruses, with the appearance of new human 
endangering virus every around 10 years (6).

Four subfamilies of CoVs, namely alpha-, beta-, gamma- and delta coronaviruses exist (1). However, HCoVs belong to only two families, alpha and beta only (7). More interestingly, the three strains associated with severe respiratory symptoms in human belong to only the beta family (4).

Among these $7 \mathrm{HCoVs}$ members known to infect humans, four (namely HCoV-229E, HCoV-NL63, HCoVOC43 and HCoV-HKU1) are globally circulated in the human population causing generally mild symptoms and contribute to around one-third of common cold infections in humans. However, they may also cause life-threatening pneumonia and bronchiolitis in a minority of cases; especially in elderly, children and immunocompromised patients $(5,8)$. In some uncommon situations, they also may cause some enteric and neurological diseases (9, 10). The first member of HCoVs discovered in 1966 was $\mathrm{HCoV}-229 \mathrm{E}$, one of the alpha CoVs family (11), followed by $\mathrm{HCoV}-\mathrm{OC} 43$ in 1967, which belongs to the beta family (8). The third member was the alpha family member HCoV-NL63, discovered in 2004 (11) and the fourth one was the beta family member HCoV-HKU1, discovered in 2005 (12).

In late 2002, the fifth member of the HCoVs had been identified, namely severe acute respiratory syndrome coronavirus (SARS-CoV) (11). It was first discovered in Guangdong, China as atypical pneumonia marked by fever, headache and subsequent onset of respiratory symptoms such as cough and pneumonia, which may later develop into life-threatening respiretory failure and acute respiratory distress syndrome. This virus affected around 8000 patients in around 29 countries within a few months, and killed around $10 \%$ of the affected cases, mostly due to acute respiratory distress syndrome (13). The origin of this new virus was first thought to be palm civets which were thought to be the natural reservoir for the virus, but later on, genome-based studies pointed to the bat origin of SARS-CoV due to the presence of genetically similar SARS-like virus in bats (14).

In 2012, the sixth member of the HCoVs appeared in Saudi Arabia and named: the Middle East respiratory syndrome coronavirus (MERS-CoV). This type was highly fatal, with around $40 \%$ mortality rate. However, it had limited spread and affected so far around 2000 patients only, most of the$m$ in Saudi Arabia (15-17). The origin of MERS-CoV was blamed to be bats also, but most of the studies linked this member to camel and camel handling $(18,19)$.

In $31 / 12 / 2019$, the newest (seventh) member of the HCoVs family first discovered in Wuhan, China, with the diagnosis of seven cases with acute severe pneumonia of unknown cause, which within few days, affected a total of around 44 cases. The causative organism was isolated from patients and was found to be a new member of the HCoVs (20). This new member was named by the World Health Organization (WHO) as the 2019 novel coronavirus (2019-nCoV) in early January 2020 , but on $11 / 2 / 2020$, the WHO formally named this new virus as COrona VIrus Disease 2019, which is abbreviated as (COVID-19) (21).

On 30/1/2020, the WHO announced the new coronavirus epidemic a public health emergency of international concern and on $11 / 3 / 2020$, it considered COVID-19 as being pandemic (22-24). 
The COVID-19 pandemic is now rapidly growing, with around 13 million infected persons and over 570,000 deaths all over the world. COVID-19 reached 206 countries. However, the distribution of COVID19 cases differs markedly according to different countries, being mostly distributed among USA, Brazil, India and Russia, and least among subSaharan Africa (25).

The temporal differences between different world regions also matter. The epidemic started in China in late December 2019, reached its maximum in January and February 2020 and started to decline in March 2020. Contrarily, the epidemic started in Europe since late February 2020, reached its maximum in April and May and then started to decline. The pandemic started even later in in the USA, Egypt and Middle east, reached its maximum in June and probably is now starting to decline. Othe countries are still in the rising phase of the epidemic, such as Brazil and India. On the other hand, some countries did not reach the spread numbers of nationwide epidemic although started to record COVID-19 cases very early, such as Japan (25).

These differences are likely to be due to true unknown factors and can not just be attributed to the differences in the screening methods among different countries because the numbers of severe cases and even deaths also runs differently among different global regions.

A second important observation regarding COVID-19 pandemic is that most of the subjects diagnosed as COVID-19 carriers depending on PCR analysis are non-symptomatic and diagnosed only during the screening of contacts of known COVID-19 patients. This raises an important question about the actual size of the unseen part of the iceberg. The fact that the first cases diagnosed in Wuhan all had acute severe respiratory symptoms put a serious hypothesis that the virus may be present inside human bodies long time before the actual discovery of it (20). The multiplicity of cases with similar symptoms in Wuhan may be the cause that struggled the doctors facing these patients to search for the unknown pathogen that caused these symptoms; but can we hypothesize that existence of only one case at a time affected by severe acute respiratory symptoms and passed unnoticed either by recovery or by death would seldom trigger specific research for the causative organism; and can we hypothesize that this scenario might have occurred many times in different parts of the world which means simply that COVID-19 was present long time before its discovery in late 2019?

Personal experience in the Rheumatology Department may support my idea. We were asked to see a male patient in late December 2019 by a colleague specialized in chest medicine. The patient was a medical person, with a history of direct contact with people from many different countries. $\mathrm{He}$ was middle-aged, diabetic and presented to chest doctors as a case of severe pneumonia and resistant fever. He received many combinations of antibiotics and antiviral therapies, but with no improvement, and finally, he needed to be ventilated. The chest specialists asked our consultation in rheumatology because they wanted to exclude or diagnose the possibility of a hidden autoimmune process that caused this severe pneumonia-like illness. Routine and immunological labs showed normal pancytopenia, high ESR and CRP, and low titre positive ANA, 
elevated creatinine level (acute renal impairment). Otherwise, no specific autoimmune disease could be diagnosed. We advised to give him pulse steroid therapy along with the combination of strong wide-spectrum antibiotics and antiviral therapies. Our diagnosed was hazy, with the possibility of severe SLE, we gave him steroid as a trial to save his life. Surprisingly, the patient started to improve gradually and fully recovered within a few weeks. Knowing some idea about the pathogenesis of COVID-19 disease and the role of cytokine storm in some cases raised this question in our minds: Could this patient be an undiagnosed COVID-19 case?

I did some non-formal questionnaire with many colleagues in the field of chest medicine and rheumatology if any of them faced with similar cases in the last few months, and I was surprised that the vast majority of those shared the questionnaire have seen at least one similar case. Many of these cases died with an undiagnosed cause of severe pneumonia, but some of them survived and recovered.

I then searched the literature if there is any solid data to support my hypothesis, but I failed to find such data. Instead, some non-formal data that when the blood donors in Castiglione d'Adda in Italy were tested for COVID-19 antibodies, $70 \%$ of them were positive (26).

So, my hypotheses are:

1. COVID-19 may be present inside human beings long before its actual discovery in late 2019, and many of the undiagnosed severe respiratory symptoms may have COVID-19.

2. The actual prevalence of COVID-19 may be much wider than the recorded numbers all over the world, and this means that the mortality rate of this virus is much lower than recorded because many cases may pass asymptomatic and not included in the total number of COVID-19 cases.

3. We may have reached already the herd immunity target, and COVID19 may have reached its peak spread, especially in countries with earlier exposure to it.

4. The origin of COVID-19 may not from Wuhan at all, and it may not from an animal origin, but rather, it may be due to some mutations of one of the already known 6 members of HCoVs. Finally, I recommend:

1. To collect at much as possible of the recovered severe atypical pneumonia cases in the last few months and even years and to test them for the presence of specific IgG COVID-19 antibodies.

2. To do random testing of normal subjects, who were never diagnosed as COVID-19 before, for the presence of COVID-19 antibodies also.

\section{References:}

1. Velavan TP, Meyer CG. The COVID19 epidemic. Tropical medicine \& international health : TM \& IH. 2020;25(3):278-80.

2. Pene F, Merlat A, Vabret A, Rozenberg F, Buzyn A, Dreyfus F, et al. Coronavirus 229E-related pneumonia in immunocompromised patients. Clinical infectious diseases : an official publication of the Infectious Diseases Society of America. 2003;37(7):92932.

3. Vijgen L, Keyaerts E, Moes E, Maes P, Duson G, Van Ranst M. Development of one-step, real-time, quantitative reverse transcriptase PCR assays for absolute quantitation of human 
SOHAG MEDICAL JOURNAL

Vol. 24 No. 3 July 2020 coronaviruses OC43 and 229E. Journal of clinical microbiology. 2005;43(11):5452-6.

4. Shereen MA, Khan S, Kazmi A, Bashir N, Siddique R. COVID-19 infection: origin, transmission, and characteristics of human coronaviruses. Journal of Advanced Research. 2020.

5. van der Hoek L. Human coronaviruses: what do they cause? Antiviral therapy. 2007;12(4 Pt B):651-8.

6. Jones BA, Grace D, Kock R, Alonso S, Rushton J, Said MY, et al. Zoonosis emergence linked to agricultural intensification and environmental change. Proc Natl Acad Sci U S A. 2013;110(21):8399-404.

7. Lim YX, Ng YL, Tam JP, Liu DX. Human Coronaviruses: A Review of Virus-Host Interactions. Diseases. 2016;4(3).

8. Walsh EE, Shin JH, Falsey AR. Clinical impact of human coronaviruses 229E and OC43 infection in diverse adult populations. The Journal of infectious diseases. 2013;208(10):1634-42.

9. Jacomy H, Fragoso G, Almazan G, Mushynski WE, Talbot PJ. Human coronavirus OC43 infection induces chronic encephalitis leading to disabilities in BALB/C mice. Virology. 2006;349(2):335-46.

10.McKay LA, Meachem M, Snead E, Brannen T, Mutlow N, Ruelle L, et al. Prevalence and mutation analysis of the spike protein in feline enteric coronavirus and feline infectious peritonitis detected in household and shelter cats in western Canada. Canadian journal of veterinary research $=$ Revue canadienne de recherche veterinaire. 2020;84(1):18-23.
11.McBride R, Fielding BC. The role of severe acute respiratory syndrome (SARS)-coronavirus accessory proteins in virus pathogenesis. Viruses. 2012;4(11):2902-23.

12.Gorse GJ, O'Connor TZ, Hall SL, Vitale JN, Nichol KL. Human coronavirus and acute respiratory illness in older adults with chronic obstructive pulmonary disease. The Journal of infectious diseases. 2009;199(6):847-57.

13.Graham RL, Donaldson EF, Baric RS. A decade after SARS: strategies for controlling emerging coronaviruses. Nat Rev Microbiol. 2013;11(12):83648.

14.Hu B, Ge X, Wang LF, Shi Z. Bat origin of human coronaviruses. Virol J. 2015;12:221.

15.Kim Y, Cheon S, Min CK, Sohn KM, Kang YJ, Cha YJ, et al. Spread of Mutant Middle East Respiratory Syndrome Coronavirus with Reduced Affinity to Human CD26 during the South Korean Outbreak. mBio. 2016;7(2):e00019.

16. Oboho IK, Tomczyk SM, Al-Asmari AM, Banjar AA, Al-Mugti H, Aloraini MS, et al. 2014 MERS-CoV outbreak in Jeddah-a link to health care facilities. New England Journal of Medicine. 2015;372(9):846-54.

17. Korean Society of Infectious D, Korean Society for Healthcare-associated Infection $\mathrm{C}, \quad$ Prevention. An Unexpected Outbreak of Middle East Respiratory Syndrome Coronavirus Infection in the Republic of Korea, 2015. Infect Chemother. 2015;47(2):120-2.

18.Farag E, Sikkema RS, Mohamedani AA, de Bruin E, Munnink BBO, Chandler $\mathrm{F}$, et al. MERS-CoV in Camels but Not Camel Handlers, 
Sudan, 2015 and 2017. Emerg Infect Dis. 2019;25(12):2333-5.

19.Alshukairi AN, Zheng J, Zhao J, Nehdi A, Baharoon SA, Layqah L, et al. High Prevalence of MERS-CoV Infection in Camel Workers in Saudi Arabia. mBio. 2018;9(5).

20.Lee A. Wuhan novel coronavirus (COVID-19): why global control is challenging? Public Health. 2020;179:A1-A2.

21.Sun P, Lu X, Xu C, Sun W, Pan B. Understanding of COVID-19 based on current evidence. Journal of medical virology. 2020.

22. Watkins J. Preventing a covid-19 pandemic. British Medical Journal Publishing Group; 2020.

23.Bossi F. Pandemic upends college experience.
24.Israil M. Review on Novel Corona Virus (nCOVID or COVID-19): Worldwide Pandemic. Available at SSRN 3566747. 2020.

25.www.worldometers.info.

https://www.worldometers.info/coron avirus/ July 12, 2020 [

26.https://www.lastampa.it. https://www.lastampa.it/topnews/pri mopiano/2020/04/02/news/coronaviruscastiglione-d-adda-e-un-caso-distudio-il-70-dei-donatori-di-sangue-epositivo1.38666481/amp/?_twitter_impressi on=true\&fbclid=IwAR3MZybfnDHtsLqP TTXKwgUghI3NL_P4ZsmebkSK9NYOV9PFQIIGF1Ov Ho 2020 April, 2 [ 